\title{
MAPA DE RECONHECIMENTO GEOLÓGICO DA BACIA DO RIO UBERABINHA (MG): PROCEDIMENTO EXPERIMENTAL UTILIZANDO COEFICIENTES DE CONCORDÂNCIA
}

\author{
Rafael Mendes Rosa \\ Universidade Federal de Uberlândia - UFU \\ Doutorando, Instituto de Geografia \\ rafaelmendesr@hotmail.com \\ Vanderlei de Oliveira Ferreira \\ Universidade Federal de Uberlândia - UFU \\ Professor Doutor, Instituto de Geografia \\ vanderlei.ferreira@ufu.br \\ Jorge Luís Silva Brito \\ Universidade Federal de Uberlândia - UFU \\ Professor Doutor, Instituto de Geografia \\ jbrito@ufu.br
}

\section{RESUMO}

Os mapas geológicos, elementares a diversas finalidades, podem ser elaborados por meio da utilização de técnicas de geoprocessamento e geotecnologias como o Geographic Information System (GIS), sensoriamento remoto e o Global Positioning System (GPS). Essas ferramentas podem apresentar bons resultados, sobretudo com informações obtidas em campo, etapa indispensável quando utilizados coeficientes de concordância. Existem grupos de mapas geológicos definidos pela escala. Os mapas de reconhecimento, por exemplo, são confeccionados na escala de 1:250.000 ou menor. Assim, o presente artigo propõe um procedimento experimental para mapas de reconhecimento geológico, aplicado na bacia do rio Uberabinha (MG) com a reclassificação dos intervalos altimétricos a partir das cotas dos contatos litológicos captadas em campo por receptor GPS. O resultado foi comparado com o mapa geológico do Projeto Triângulo Mineiro em escala 1:100.000. Com esses mapas, foi analisada a qualidade de ambos por meio dos coeficientes de concordância total, Kappa e Tau, o que contribuiu para a elaboração de um mapa de reconhecimento geológico da área de estudo. Ressalta-se que esses procedimentos podem ser uma alternativa para a confecção de mapas geológicos em outras bacias hidrográficas em contextos geotectônicos semelhantes.

Palavras-chave: Mapeamento geológico. Bacia do rio Uberabinha. Geoprocessamento. Geotecnologias. Coeficientes de concordância.

\section{GEOLOGICAL RECONNAISSANCE MAP OF UBERABINHA RIVER BASIN (MINAS GERAIS STATE, BRAZIL): EXPERIMENTAL PROCEDURE USING COEFFICIENTS OF AGREEMENT}

\section{ABSTRACT}

Geological maps, for various purposes, can be elaborated by means of geoprocessing techniques and geotechnologies such as Geographic Information System (GIS), remote sensing and Global Positioning System (GPS). These tools can present good results, especially with the information obtained in the field, indispensable stage when are employed coefficients of agreement. There are groups of geological maps organized by scale. Recognition maps, for example, are made on the scale of 1: 250,000 or lower. Therefore, the present article suggests an experimental procedure for geological reconnaissance maps, applied in the Uberabinha river basin (MG) with a reclassification of the altimetric intervals from the databases collected in field GPS receiver. The result was compared with the geological map of the Triângulo Mineiro Project in scale 1:100,000. With these maps, the quality of both was analyzed throug total, Kappa and Tau coefficients of agreement, which contributed to the elaboration of a geological recognition map of the studied area. It is important to emphasize that these procedures may be an alternative for the preparation of geological maps in other watersheds in a similar geotectonics contexts.

Key-words: Geological mapping. Uberabinha river basin. Geoprocessing. Geotechnologies. Coefficients of agreement. 
Mapa de reconhecimento geológico da bacia do rio Uberabinha (MG): procedimento experimental utilizando coeficientes de concordância

\section{INTRODUÇÃO}

A caracterização geológica de uma determinada unidade territorial corresponde a uma das atividades elementares nos estudos da paisagem e, por conseguinte, proporciona subsídios ao planejamento ambiental, principalmente quando associada a ferramentas tecnológicas importantes, como o Geographic Information System (GIS). Além disso, trata-se da base dos estudos integrados da geografia física, pois as características do substrato condicionam o relevo, a rede de drenagem e as tipologias de solos. Os contatos litológicos expressam, por exemplo, contrastes paisagísticos, sendo, portanto, um primeiro passo para a compartimentação de áreas distintas, que podem apresentar diferentes potencialidades e vulnerabilidades (ROSA, 2017).

Os mapas geológicos do território brasileiro, disponíveis de forma gratuita, se encontram em escala pequena, inviabilizando estudos que exigem mapas de maior detalhe devido ao alto custo para sua elaboração. Recentemente o estado de Minas Gerais tem disponibilizado mapas geológicos em escala de 1:100.000 da Companhia de Desenvolvimento Econômico de Minas Gerais (CODEMIG) em parceria com a Universidade Federal de Minas Gerais (UFMG). Entretanto, mesmo com algumas iniciativas por parte do poder público, o levantamento de mapas geológicos com informações confiáveis ainda é um desafio. Nesse sentido, tal problemática pode ser parcialmente resolvida com pesquisas voltadas à utilização de geotecnologias, trabalhos de campo dirigidos e análise estatística, diminuindo os custos e obtendo-se bons resultados.

A partir desse enfoque, inicialmente é necessário o conhecimento geológico nas diferentes escalas (regional e local) para a obtenção das litologias, a experiência prática de observação de tais características in loco e o domínio de geotecnologias. Considera-se importante a escala de trabalho na identificação das formações geológicas, uma vez que o conhecimento em âmbito regional contribui na obtenção de premissas básicas para, posteriormente, buscar os detalhes na área de estudo. A experiência de observação da paisagem e a captação de pontos em campo pelo receptor Global Positioning System (GPS) potencializa a aquisição de informações corretas para serem utilizadas em software de geoprocessamento e a respectiva confecção de mapas.

Para diferenciar os termos geoprocessamento e GIS, Rosa (2007) considera que o primeiro apresenta um conceito mais abrangente e pode envolver qualquer processamento de dados georreferenciados, enquanto o segundo compreende as geotecnologias e está relacionado ao processamento tanto de dados gráficos quanto não gráficos, destacando-se análises espaciais e modelagens de superfícies. O geoprocessamento compreende técnicas de tratamento da informação espacial como a coleta, armazenamento, análise e uso integrado, o que incide em procedimentos matemáticos e computacionais, sendo, portanto, imprescindível a utilização de um software para a aplicação de tais técnicas na produção de mapas, cartogramas, entre outros.

Os mapas geológicos, elementares a diversas finalidades, podem ser elaborados por meio da utilização de técnicas de geoprocessamento e geotecnologias como o GIS, sensoriamento remoto e o GPS. O aproveitamento dos mesmos consiste em uma ferramenta fundamental para a qualidade do trabalho, sobretudo quando aplicado em interface com as informações obtidas em campo. Embora tenham procedimentos metodológicos que os utilizem, é importante a apresentação de alternativas que subsidiem esses levantamentos. De acordo com Lisle et al. (2014), mapas de reconhecimento geológico, por exemplo, podem ser elaborados a partir da interpretação de imagens de satélite associada com modelos digitais de terreno e a identificação de rochas em campo.

Conforme apresentam Lisle et al. (2014), existem quatro grupos de mapas geológicos, que são de reconhecimento, regionais, detalhados e especiais. Basicamente a escala adotada os define e cada um possui uma finalidade distinta. Os mapas de reconhecimento são confeccionados na escala de 1:250.000 ou menor e são uma fonte de informação generalizada, porém obtida de maneira mais rápida. Os regionais em muitos casos são trabalhados na escala de 1:100.000 e fornecem uma melhor distribuição das rochas. Os detalhados possuem escala de 1:10.000 ou maiores e servem para solucionar problemas específicos, como exploração mineral ou ainda 
Mapa de reconhecimento geológico da bacia do rio Uberabinha (MG): procedimento experimental utilizando coeficientes de concordância
Rafael Mendes Rosa Vanderlei de Oliveira Ferreira Jorge Luís Silva Brito

implantação de grandes projetos de engenharia. Por fim, os especiais possuem escala grande de áreas muito pequenas e são voltados às mesmas finalidades dos mapas detalhados.

Dessa forma, o presente artigo possui o intuito de propor um procedimento metodológico experimental para mapas de reconhecimento geológico, aplicado na bacia do rio Uberabinha (estado de Minas Gerais). O trabalho consistiu na reclassificação dos intervalos altimétricos das curvas de nível obtidas por imagens Shuttle Radar Topography Mission (SRTM) a partir das cotas dos contatos litológicos captadas em campo por receptor GPS. O resultado foi comparado com o mapa geológico do Projeto Triângulo Mineiro da CODEMIG (2017). Ao final, foi realizada uma comparação da qualidade dos produtos, sendo apresentada uma alternativa de mapeamento em escala de reconhecimento.

\section{ÁREA DE ESTUDO}

A área de estudo é a bacia do rio Uberabinha, localizada na mesorregião do Triângulo Mineiro e Alto Paranaíba (estado de Minas Gerais). Conforme Rosa (2017), a bacia possui uma área de $2.190,65 \mathrm{~km}^{2}$ distribuídos em três municípios, cerca de $20 \%$ em Uberaba, $70 \%$ em Uberlândia e 10\% em Tupaciguara (Figura 1). O rio principal é afluente da margem esquerda do rio Araguari, que por sua vez deságua no rio Paranaíba. O rio Uberabinha é um importante manancial devido ao abastecimento público da cidade de Uberlândia, que possui uma população superior a 600.000 habitantes (IBGE, 2010). As cartas topográficas em escala 1:100.000 que abrangem a bacia são: Folha SE-23-Y-C-I (Nova Ponte), Folha SE-22-Z-D-III (Miraporanga), Folha SE-22-Z-B-VI (Uberlândia) e Folha SE-22-Z-B-V (Tupaciguara).

Figura 1 - Localização da bacia do rio Uberabinha.

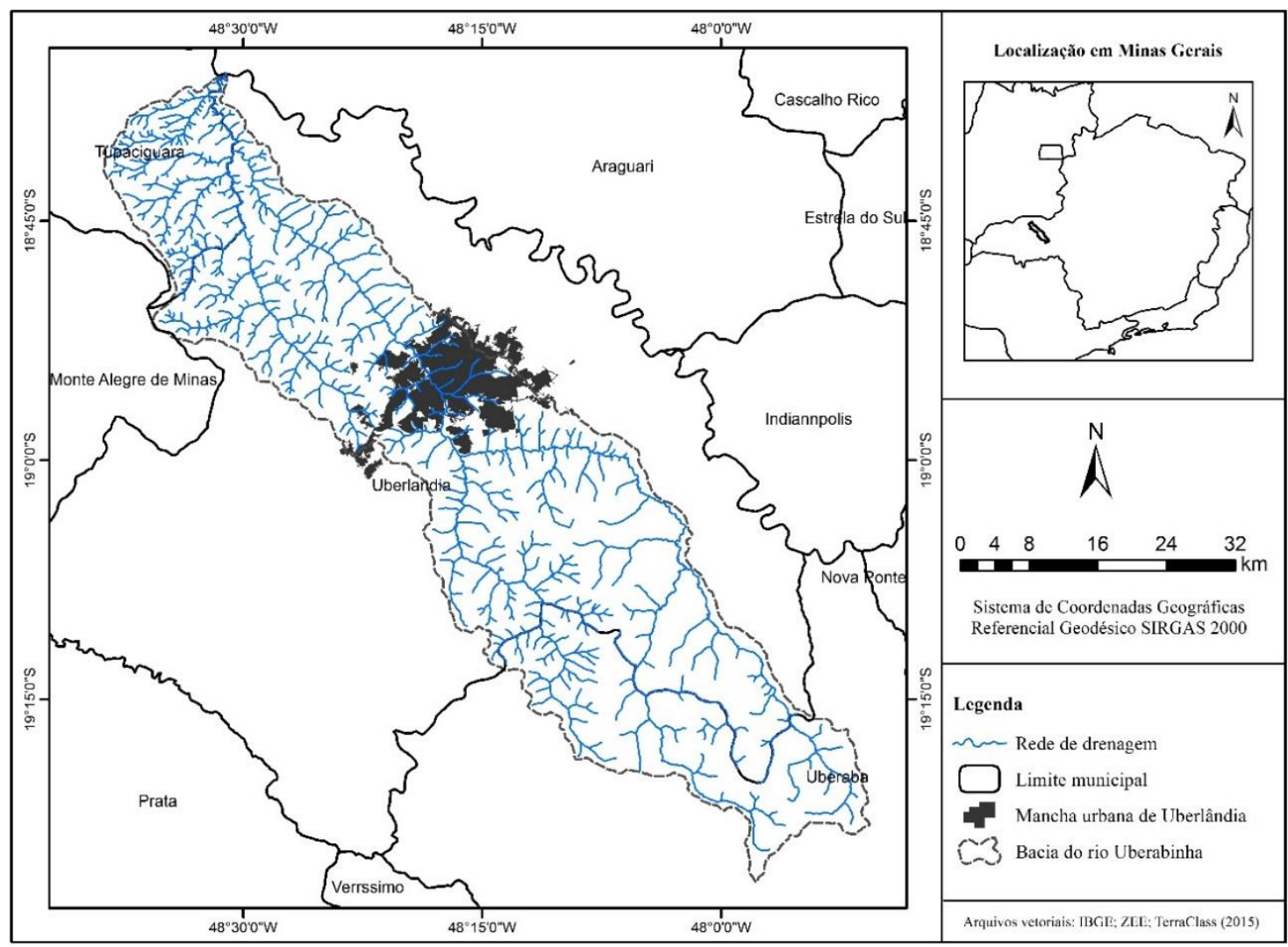

Fonte - Elaborado pelos autores (2018).

\section{PROCEDIMENTOS METODOLÓGICOS E MATERIAIS UTILIZADOS}

O trabalho consistiu inicialmente em um levantamento bibliográfico sobre as características geológicas da área de estudo, sendo apresentadas referências que abordam os contextos 
Mapa de reconhecimento geológico da bacia do rio Uberabinha (MG): procedimento experimental utilizando coeficientes de concordância

regional e local. De modo complementar também foram consultados mapas geológicos, cartas topográficas e imagens de satélite, que contribuíram para as análises in loco e a confecção dos mapas, sendo utilizado o software ArcGIS 10.1, desenvolvido pela Environmental Systems Research Institute (ESRI). A litoestratigrafia foi representada nos mapas pelo código de cores RGB de Pellé (2012), que corresponde a uma padronização da escala de tempo geológica. Após a caracterização, foi realizada uma reclassificação dos intervalos altimétricos das curvas de nível a partir de imagens SRTM, cuja articulação é compatível com a escala 1:250.000. Como foram obtidas no site do Serviço Geológico dos Estados Unidos (USGS, 2018), a resolução espacial é de $30 \mathrm{~m}$. As imagens correspondem às folhas SE-22-Z-B, SE-23-Y-A, SE22-Z-D e SE-23-Y-C.

Essa reclassificação foi baseada nas cotas dos contatos litológicos captadas em campo (pontos de observação) com a utilização de um receptor GPS (acurácia de $10 \mathrm{~m}$ na horizontal e $20 \mathrm{~m}$ na vertical) para aquisição das coordenadas geográficas e da altimetria, sendo cada intervalo nomeado com a formação identificada pelas referências bibliográficas e confirmadas in loco (Quadro 1). Ressalta-se que os trabalhos de campo para obtenção dos pontos de observação foram dirigidos, pois caso fosse adotado um critério aleatório as amostragens ficariam desproporcionais devido às áreas de abrangência das litologias. O resultado desse procedimento experimental foi comparado com o mapa geológico do Projeto Triângulo Mineiro (CODEMIG, 2017) em escala de 1:100.000.

Quadro 1 - Intervalos altimétricos utilizados na reclassificação do mapa de geologia.

\begin{tabular}{|l|c|}
\hline \multicolumn{1}{|c|}{ Unidades geológicas } & Intervalo reclassificado \\
\hline Cobertura detrítico-laterítica & Acima de $940 \mathrm{~m}$ \\
\hline Formação Marília & Entre 840 e $940 \mathrm{~m}$ \\
\hline Formação Serra Geral & Entre 570 e $840 \mathrm{~m}$ \\
\hline Grupo Araxá & Abaixo de $570 \mathrm{~m}$ \\
\hline
\end{tabular}

Fonte - Adaptado de Rosa (2017).

Para a elaboração do mapa de reconhecimento geológico foram reclassificados intervalos altimétricos a partir do mosaico das imagens SRTM e a extração da bacia hidrográfica do rio Uberabinha, principalmente com procedimentos na caixa de ferramentas Spatial Analyst Tools. Em seguida, foi obtido uma representação tridimensional do terreno (bacia e adjacências) com extração das curvas de nível com equidistância de $5 \mathrm{~m}$ para refinamento e obtenção de melhores resultados. Com esse procedimento foi possível a criação do Triangulated Irregular Network (TIN) e a respectiva conversão para imagem raster, ações disponíveis no 3D Analyst Tools. Após o recorte do raster para a área de estudo foi realizada a reclassificação dos intervalos altimétricos mencionados e a conversão para shapefile. Em relação ao mapa da CODEMIG, foram utilizados simplesmente os arquivos vetoriais da geologia com recorte para a bacia.

Os materiais utilizados em campo foram um receptor GPS Garmin Etrex 20 e um notebook para análise de imagens off-line do Google Earth Pro. Os pontos de observação (70 pontos) foram gravados no referido receptor GPS para serem plotados nos mapas geológicos e serem utilizados na análise dos mesmos, por meio de coeficientes de concordância, e também para elaboração do mapa final. Esse último corresponde às informações dos dois mapas, análise desses coeficientes, além de adequações necessárias devido às observações diretas e indiretas em campo. As diretas correspondem à afloramentos naturais ou de intervenção antrópica. As indiretas são análises de aspectos da paisagem, por exemplo a coloração e textura do solo, a posição topográfica, entre outros, que indicam grande possibilidade de ocorrência de determinado litotipo, sendo realizadas quando não foram encontrados nenhum afloramento.

De acordo com Rosa (2007), os principais coeficientes de concordância adotados na avaliação da acuraria total do mapa são a concordância total, o coeficiente de concordância Kappa e o coeficiente de concordância Tau. A utilização concomitante desses coeficientes no trabalho permitiu uma maior confiabilidade do mapa final, sendo um refinamento dos anteriores, que 
Mapa de reconhecimento geológico da bacia do rio Uberabinha (MG): procedimento experimental utilizando coeficientes de concordância
Rafael Mendes Rosa Vanderlei de Oliveira Ferreira Jorge Luís Silva Brito

foram avaliados por tais coeficientes. Para efetivação dos procedimentos foi utilizada uma matriz de erros, que deve levar em consideração a amostragem por pontos obtidos em campo (Figura 2), cujos dados foram empregados em conformidade com cada coeficiente.

Figura 2 - Pontos de observação em campo.

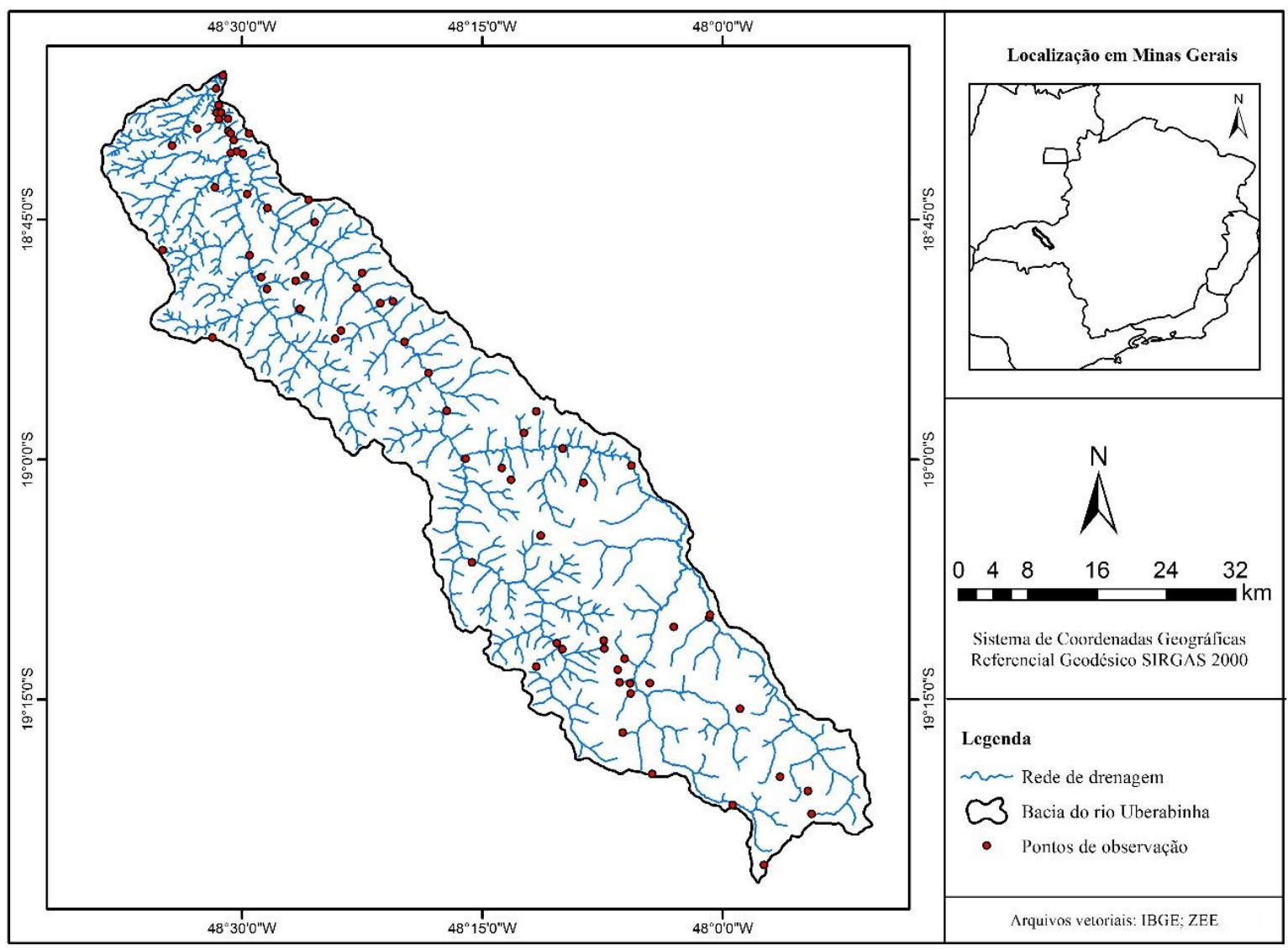

Fonte - Elaborado pelos autores (2018).

A concordância total $(P o)$ é dada pela razão do somatório da diagonal principal $\left(\sum X_{i}\right)$ pelo número de amostras $(\mathrm{N})$, variando de 0 a 1 , conforme a equação 1 . O coeficiente de concordância Kappa ( $k$ ) é obtido pela equação 2, onde $P c$ é o somatório das linhas e colunas marginais dividido pelo total de observações ao quadrado. Convertendo-se os valores da matriz de erros da concordância total em porcentagem, tem-se o $P c$ mediante a equação 3 , sendo $P c$ o somatório dos percentuais das linhas e colunas marginais dividido pelo percentual total de observações ao quadrado. A estatística Kappa é utilizada para analisar a concordância entre um mapa temático e a verdade terrestre, elaborada por meio de amostragens de campo. A qualidade do mapa pode ser avaliada pelos seguintes valores: 0,0 e 0,2 (ruim); 0,2 e 0,4 (razoável); 0,4 e 0,6 (bom); 0,6 e 0,8 (muito bom); e 0,8 e 1,0 (excelente). Por último, o coeficiente de concordância Tau (T), apresentado na equação 4, é similar ao coeficiente de concordância Kappa (k), sendo que Pré 1 / $n$ e n é o número de classes (ROSA, 2007).

Coeficiente de concordância total $(P o)$ :

$P o=\frac{\Sigma X_{\mathrm{i}}}{\mathrm{N}}$ 
Coeficiente de concordância Kappa (k):

$k=\frac{P o-P c}{1-P c}$

Proporção de elementos atribuídos a determinada classe ao acaso $(P C)$ :

$P c=\frac{\left(L_{1} C_{1}+L_{2} C_{2}+\ldots+L_{n} C_{n}\right)}{N^{2}}$

Coeficiente de concordância $\operatorname{Tau}(T)$ :

$T=\frac{P o-P r}{1-P r}$

\section{RESULTADOS E DISCUSSÕES}

Inicialmente é apresentado o levantamento geológico da área de estudo, seguido dos resultados dos coeficientes de concordância dos mapas geológicos e as respectivas discussões e, por fim, a adequação do mapa com base na verdade terrestre.

\section{Caracterização da geologia da bacia do rio Uberabinha}

De acordo com Nishiyama (1989), o Triângulo Mineiro (região onde se situa a bacia do rio Uberabinha) encontra-se praticamente inserido na porção nordeste da Bacia Sedimentar do Paraná, que corresponde a uma ampla região sedimentar da América do Sul, abrangendo porções territoriais do Brasil meridional, Paraguai oriental, nordeste da Argentina e norte do Uruguai (MILANI et al. 2007). O embasamento estrutural é composto por rochas PréCambrianas formadas por ativação tectônica, seguido de litologias de idade Mesozóica formadas pelo extravasamento de lavas (rochas magmáticas) e por sedimentação (rochas sedimentares).

$\mathrm{Na}$ bacia do rio Uberabinha, o embasamento litológico corresponde aos metassedimentos dobrados e falhados do Grupo Araxá (Proterozóico), associados à Faixa de Dobramentos Brasília (DARDENNE, 2000). A gênese desse grupo está relacionada à erosão do complexo granito-gnáissico, cuja sedimentação sofreu metamorfismo regional devido aos movimentos tectônicos. Segundo Barbosa et al. (1970, p. 21), o Grupo Araxá corresponde a um "grupo de metamorfitos de fácies epidoto-afibolito, consistindo essencialmente de micaxistos e quartzitos, com intercalações de anfibolitos". Nishiyama (1989) ressalta que essas rochas se encontram sotopostas às litologias de idade Mesozóica, cujas exposições ocorrem em áreas intensamente erodidas pela ação fluvial. Os afloramentos do Grupo Araxá na bacia do rio Uberabinha ocorrem no trecho final do curso d'água principal, onde há uma zona de contato com a Formação Serra Geral, ampliando-se ao longo do vale encaixado até a sua foz. Os micaxistos encontrados apresentam dobras, microdobras, falhas e fraturas. Nas escarpas abruptas, essas rochas estão expostas à ação do intemperismo, apresentando-se bastante friáveis.

As litologias de idade Mesozóica são compostas pelo Grupo São Bento, constituído de rochas magmáticas intercaladas com formações sedimentares; e Grupo Bauru, formado por litologias exclusivamente sedimentares. Segundo Feltran Filho (1997), a presença das rochas desses grupos está relacionada à resistência dos seus constituintes frente aos processos de erosão geoquímica diferencial (corrosão, lixiviação e movimentos de remoção), atuantes no Cenozóico.

O Grupo São Bento é constituído pelas rochas Juro-Cretáceas das Formações Botucatu (rochas sedimentares) e Serra Geral (rochas magmáticas básicas). Ao contrário da Formação Serra Geral, os arenitos eólicos da Formação Botucatu não são representativos na área de estudo, devido aos afloramentos serem bastante restritos. Tais arenitos assentam-se sobre 0 
Mapa de reconhecimento geológico da bacia do rio Uberabinha (MG): procedimento experimental utilizando coeficientes de concordância

embasamento e também de forma intercalada com os basaltos (constituindo lentes de arenito intertrapeano) e/ou subjacente ao Grupo Bauru (NISHIYAMA, 1989).

A Formação Serra Geral é composta de rochas efusivas básicas, cuja formação remete a intensa atividade vulcânica ocorrida na Bacia do Paraná durante o Mesozóico, atingindo áreas das regiões Sul, Centro Oeste e Sudeste do país (NISHIYAMA, 1989). Tratam-se de basaltos, que apresentam coloração escura, textura afanítica (cristais de pequena dimensão em função do rápido arrefecimento), fraturas e disjunções colunares em derrames espessos. Na bacia do rio Uberabinha os basaltos encontram-se recobertos pelo Grupo Bauru na porção da chapada. Seus afloramentos iniciam-se a partir da cachoeira do Sucupira, estendendo ao longo da calha do rio Uberabinha até a cachoeira Malagone. Essas rochas também afloram em parte do leito do ribeirão Bom Jardim e do rio das Pedras, ambos afluentes da margem esquerda do rio principal.

O Grupo Bauru é composto de rochas sedimentares de idade Cretácea correspondentes às Formações Uberaba, Adamantina e Marília na região do Triângulo Mineiro, embora somente a última encontra-se presente na área de estudo. De acordo com Batezelli (2003), esse grupo corresponde à unidade suprabasáltica que permaneceu preservada, apresentando espessuras diferenciadas após movimentações tectônicas. O encerramento da sedimentação que originou do Grupo Bauru coincide com o fim da Era Mesozóica na Bacia Sedimentar do Paraná.

$\mathrm{Na}$ bacia do rio Uberabinha, o Grupo Bauru é representado pela Formação Marília, que segundo Nishiyama (1989) é caracterizada por camadas espessas de arenitos e conglomerados dispostos sob níveis carbonáticos. Para Barcelos (1984), essa formação se desenvolveu em regimes torrenciais referentes aos leques aluviais de clima semiárido, sendo dividida em três membros: Ponte Alta, Serra da Galga e Echaporã. Entretanto, na área de estudo encontram-se somente os dois primeiros, abrangendo principalmente a porção da chapada Uberlândia-Uberaba.

O Membro Ponte Alta, parte inferior da Formação Marília, apresenta alternância de arenitos conglomeráticos e conglomerados com seixos de quartzo e quartzito que variam de milímetros a alguns centímetros, associados à calcretes e silcretes. Tais litotipos são intensamente cimentados por carbonato de cálcio (ALVES, 1995). Para Batezelli (2003, p. 40), esse membro corresponde aos "arenitos calcíferos finos, esbranquiçados, com espessura máxima da ordem de 7 metros, que ocorrem em camadas contínuas com até $3 \mathrm{~km}$ de extensão em subsuperfície".

A subdivisão denominada Membro Serra da Galga recobre a porção das chapadas, assentada sobre o Membro Ponte Alta. Para Nishiyama (1989), esse membro é o principal representante da Formação Marília na bacia do rio Uberabinha, sendo constituído por arenitos imaturos de coloração esbranquiçada e conglomerados. Todavia, Batezelli (2003) identificou uma associação de fácies constituída por conglomerados polimíticos, branca a amarelada; arenito conglomerático amarelado com estratificações cruzadas, intercalastes de calcretes e nódulos carbonáticos.

Por fim, os depósitos detrito-lateríticos (Cenozóico) estão sobrejacentes às Formações Serra Geral e Marília. As lateritas são formações decorrentes de processos pedogenéticos em que a lixiviação do solo promove uma perda geoquímica das bases e sílica, acumulando crostas, couraças e concreções de óxidos e hidróxidos de ferro e alumínio.

\section{Resultados dos coeficientes de concordância dos mapas geológicos}

Os mapas geológicos da bacia do rio Uberabinha, elaborados por dois procedimentos distintos, apresentaram diferenças e semelhanças, conforme análise visual e também nos resultados dos coeficientes de concordância (total, Kappa e Tau). Em campo, foram captados 70 pontos de observações diretas e indiretas, sendo que dentre esses pontos, 10 compreendem ao Grupo Araxá, 20 à Formação Serra Geral, 20 à Formação Marília e outros 20 à cobertura detríticolaterítica. Dessa forma, sobrepondo-os nos mapas, foi possível contabilizar a quantidade de pontos que se encontram compatíveis com o resultado de cada mapa. Após a apresentação dos mapas geológicos da área de estudo (Figura 3) são apresentados tais resultados. 
Figura 3 - Mapas geológicos obtidos por diferentes procedimentos: (A) Mapa obtido por meio de reclassificação de intervalos altimétricos de imagem SRTM; (B) Mapa obtido por meio de recorte dos arquivos vetoriais da CODEMIG.

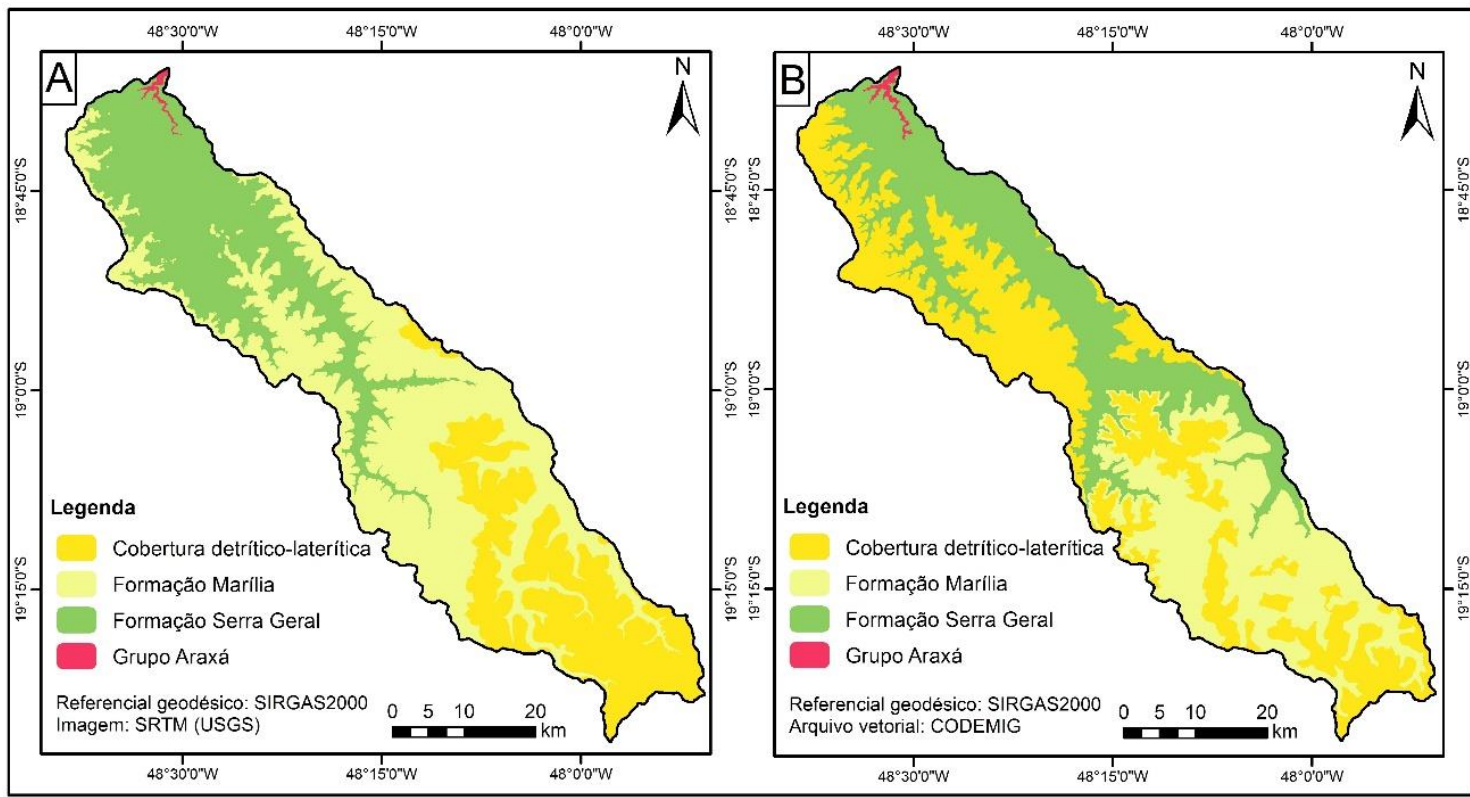

Fonte - Elaborado pelos autores (2018).

No mapa obtido pela imagem SRTM, conforme os valores da Tabela 1, obteve-se o valor do coeficiente de concordância total de $72,80 \%$. Já a concordância Kappa do referido mapa foi de $27,00 \%$, enquanto o índice Kappa tenha sido de 0,62. Esse índice indica que o mapa produzido possui uma qualidade muito boa, o que foi corroborado com o resultado da concordância Tau do mapa, que obteve 0,63 a partir do seguinte cálculo: $T=0,728-0,250 / 1-0,250=0,63$.

Tabela 1 - Avaliação dos coeficientes de concordância total e Kappa referente ao mapa geológico obtido pela imagem SRTM.

\begin{tabular}{|c|c|c|c|c|c|c|}
\hline \multicolumn{7}{|c|}{ Coeficiente de concordância total } \\
\hline \multirow{5}{*}{ 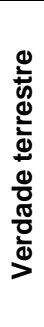 } & & $\begin{array}{l}\text { Grupo } \\
\text { Araxá }\end{array}$ & $\begin{array}{c}\text { Formação Serra } \\
\text { Geral }\end{array}$ & $\begin{array}{c}\text { Formação } \\
\text { Marília }\end{array}$ & $\begin{array}{c}\text { Cobertura detrítico- } \\
\text { laterítica }\end{array}$ & \\
\hline & $\begin{array}{l}\text { Grupo } \\
\text { Araxá }\end{array}$ & 7 & 3 & - & - & 10 \\
\hline & $\begin{array}{l}\text { Formação } \\
\text { Serra Geral }\end{array}$ & - & 20 & - & - & 20 \\
\hline & $\begin{array}{c}\text { Formação } \\
\text { Marília } \\
\end{array}$ & - & 1 & 14 & 5 & 20 \\
\hline & $\begin{array}{c}\text { Cobertura detrítico- } \\
\text { laterítica }\end{array}$ & - & 3 & 7 & 10 & 20 \\
\hline & & 7 & 27 & 21 & 15 & 70 \\
\hline \multicolumn{7}{|c|}{ Coeficiente de concordância Kappa } \\
\hline \multirow{5}{*}{ 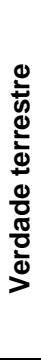 } & & $\begin{array}{l}\text { Grupo } \\
\text { Araxá }\end{array}$ & $\begin{array}{c}\text { Formação Serra } \\
\text { Geral }\end{array}$ & $\begin{array}{c}\text { Formação } \\
\text { Marília }\end{array}$ & $\begin{array}{c}\text { Cobertura detrítico- } \\
\text { laterítica }\end{array}$ & \\
\hline & $\begin{array}{l}\text { Grupo } \\
\text { Araxá }\end{array}$ & $10,0 \%$ & $4,3 \%$ & - & - & $14,3 \%$ \\
\hline & $\begin{array}{l}\text { Formação } \\
\text { Serra Geral }\end{array}$ & - & $28,6 \%$ & - & - & $28,6 \%$ \\
\hline & $\begin{array}{c}\text { Formação } \\
\text { Marília }\end{array}$ & - & $1,4 \%$ & $20,0 \%$ & $7,14 \%$ & $28,5 \%$ \\
\hline & $\begin{array}{c}\text { Cobertura detrítico- } \\
\text { laterítica }\end{array}$ & - & $4,3 \%$ & $10,0 \%$ & $14,3 \%$ & $28,6 \%$ \\
\hline & & $10,0 \%$ & $38,6 \%$ & $30,0 \%$ & $21,4 \%$ & $100,0 \%$ \\
\hline
\end{tabular}

Fonte - Elaborado pelos autores (2018). 
$\mathrm{Na}$ avaliação do coeficiente de concordância total do mapa obtido pelo shapefile da CODEMIG (Tabela 2), obteve-se um resultado de $80,00 \%$. Ainda na Tabela 2, a concordância Kappa do mapa foi de $26,50 \%$ e o valor Kappa foi de 0,72 , indicando que o mapa é muito bom. Essa qualidade também é confirmada no resultado da avaliação da concordância Tau do mapa, que foi de 0,73 , conforme cálculo a seguir: $T=0,800-0,250 / 1-0,250=0,73$.

Tabela 2 - Avaliação dos coeficientes de concordância total e Kappa referente ao mapa geológico obtido pelo arquivo vetorial da CODEMIG.

\begin{tabular}{|c|c|c|c|c|c|c|}
\hline \multicolumn{7}{|c|}{ Coeficiente de concordância total } \\
\hline \multirow{5}{*}{ 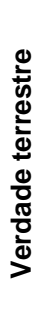 } & & $\begin{array}{l}\text { Grupo } \\
\text { Araxá }\end{array}$ & $\begin{array}{c}\text { Formação Serra } \\
\text { Geral }\end{array}$ & $\begin{array}{c}\text { Formação } \\
\text { Marília }\end{array}$ & $\begin{array}{c}\text { Cobertura detrítico- } \\
\text { laterítica }\end{array}$ & \\
\hline & $\begin{array}{l}\text { Grupo } \\
\text { Araxá }\end{array}$ & 10 & (1) & ( & (1) & 10 \\
\hline & $\begin{array}{l}\text { Formação } \\
\text { Serra Geral }\end{array}$ & - & 20 & - & - & 20 \\
\hline & $\begin{array}{c}\text { Formação } \\
\text { Marília } \\
\end{array}$ & - & 7 & 8 & 5 & 20 \\
\hline & $\begin{array}{c}\text { Cobertura detrítico- } \\
\text { laterítica }\end{array}$ & - & - & 2 & 18 & 20 \\
\hline & & 10 & 27 & 10 & 23 & 70 \\
\hline \multicolumn{7}{|c|}{ Coeficiente de concordância Kappa } \\
\hline \multirow{5}{*}{ 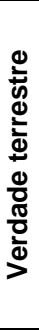 } & & $\begin{array}{l}\text { Grupo } \\
\text { Araxá }\end{array}$ & $\begin{array}{c}\text { Formação Serra } \\
\text { Geral }\end{array}$ & $\begin{array}{c}\text { Formação } \\
\text { Marília }\end{array}$ & $\begin{array}{c}\text { Cobertura detrítico- } \\
\text { laterítica }\end{array}$ & \\
\hline & $\begin{array}{l}\text { Grupo } \\
\text { Araxá }\end{array}$ & $14,3 \%$ & - & - & - & $14,3 \%$ \\
\hline & $\begin{array}{l}\text { Formação } \\
\text { Serra Geral }\end{array}$ & - & $28,6 \%$ & - & - & $28,6 \%$ \\
\hline & $\begin{array}{c}\text { Formação } \\
\text { Marília } \\
\end{array}$ & - & $10,0 \%$ & $11,4 \%$ & $7,1 \%$ & $28,5 \%$ \\
\hline & $\begin{array}{c}\text { Cobertura detrítico- } \\
\text { laterítica }\end{array}$ & - & - & 2,9 & $25,7 \%$ & $28,6 \%$ \\
\hline & & $14,3 \%$ & $38,6 \%$ & $14,3 \%$ & $32,8 \%$ & $100,0 \%$ \\
\hline
\end{tabular}

Fonte - Elaborado pelos autores (2018).

\section{Síntese dos resultados, comparações e adequação do mapa geológico}

A partir dos resultados dos coeficientes de concordância (Tabela 3), pode-se considerar que apesar dos mapas apresentem diferenças visuais, sobretudo em relação às áreas onde se encontram a cobertura detrítico-laterítica, ambos foram classificados como muito bom pela análise do valor Kappa. Tais dados, refletem, no entanto, que os mapas geológicos dependem da finalidade que o pesquisador necessita, refletindo na escala adotada no mapeamento.

Tabela 3 - Síntese dos resultados dos coeficientes para análise e comparações.

\begin{tabular}{c|c|c|c|c}
\hline \multirow{2}{*}{ Mapas geológicos } & \multicolumn{3}{|c|}{ Coeficientes de concordância } & \multirow{2}{*}{$\begin{array}{c}\text { Qualidade } \\
\text { dos mapas }\end{array}$} \\
\cline { 2 - 4 } & Total & Kappa e valor Kappa & Tau & Muito bom \\
\hline $\begin{array}{c}\text { Imagem } \\
\text { SRTM }\end{array}$ & $72,8 \%$ & $27,0 \%$ e 0,62 & 0,63 & Muito bom \\
\hline $\begin{array}{c}\text { Shapefile } \\
\text { CODEMIG }\end{array}$ & $80,0 \%$ & $26,5 \%$ e 0,72 & 0,73 & \\
\hline \multicolumn{4}{c}{ Fonte - Elaborado pelos autores (2018). }
\end{tabular}

É importante ressaltar que ambos se mostraram concordantes em sua maior parte (Tabela 4), sobretudo porque a cobertura detrítico-laterítica pode estar encoberta pela Formação Marília no mapa do shapefile da CODEMIG em boa parte das áreas discordantes entre os mapas. $O$ percentual de acerto da área ocupada por rochas do Grupo Araxá foi alto, considerando a relação da verdade terrestre com os mapas. Embora no mapa da imagem SRTM, o percentual de pontos tenha sido de $70 \%$, os outros $30 \%$ foram pontos que se encontraram na Formação Serra Geral, bastante próximo do Grupo Araxá, erro que pode ser minimizado. O percentual de acerto das áreas ocupadas pela Formação Serra Geral foi de 100\% em ambos os mapas. 
Mapa de reconhecimento geológico da bacia do rio Uberabinha (MG): procedimento experimental utilizando coeficientes de concordância
Rafael Mendes Rosa Vanderlei de Oliveira Ferreira Jorge Luís Silva Brito

Tabela 4 - Percentual de acerto dos mapas geológicos conforme os pontos de observação.

\begin{tabular}{c|c|c|c|c}
\hline $\begin{array}{c}\text { Mapas } \\
\text { geológicos }\end{array}$ & Grupo Araxá & $\begin{array}{c}\text { Formação } \\
\text { Serra Geral }\end{array}$ & Formação Marília & $\begin{array}{c}\text { Cobertura } \\
\text { detrítico-laterítica }\end{array}$ \\
\hline $\begin{array}{c}\text { Imagem } \\
\text { SRTM }\end{array}$ & $70,0 \%$ & $100,0 \%$ & $70,0 \%$ & $50,0 \%$ \\
\hline $\begin{array}{c}\text { Shapefile } \\
\text { CODEMIG }\end{array}$ & $100,0 \%$ & $100,0 \%$ & $40,0 \%$ & $90,0 \%$ \\
\hline
\end{tabular}

Fonte - Elaborado pelos autores (2018).

Esses resultados demonstraram a importância de uma avaliação dos coeficientes de concordância para elaboração de mapas com excelente qualidade, uma vez que contribuíram para a adequação do mapa de reconhecimento geológico da bacia do rio Uberabinha, para se aproximar ainda mais da verdade terrestre na escala adotada. Após serem classificados como muito bons, os dois mapas contribuíram para a elaboração de outro mapa com qualidade excelente, pois todos os pontos de observação se encontram $100 \%$ inseridos nas respectivas unidades geológicas. Dessa forma, a Figura 4 corresponde ao mapa de reconhecimento geológico da bacia do rio Uberabinha por meio do procedimento experimental apresentado.

Figura 4 - Mapa de reconhecimento geológico da bacia do rio Uberabinha.

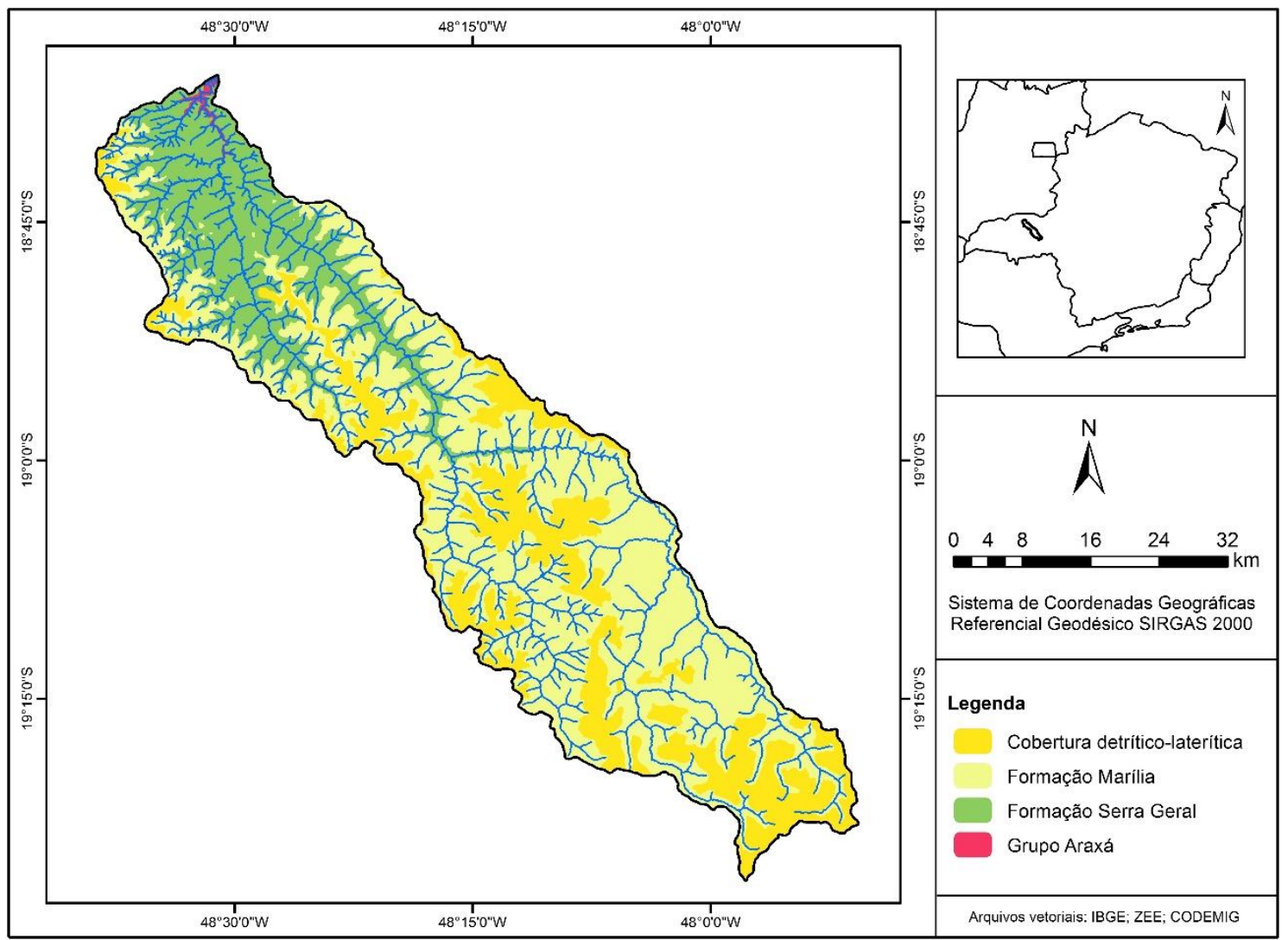

Fonte - Elaborado pelos autores (2018).

\section{CONSIDERAÇÕES FINAIS}

Os mapas geológicos são elementares para diversas finalidades, como pesquisas acadêmicas, análise da paisagem, mineração, estudos ambientais, entre outros. Contudo, boa parte do território brasileiro não se encontra mapeado com escala compatível para tais objetivos e quando estão nem sempre são validados por meio de procedimentos estatísticos. Em algumas regiões que não sofreram ações tectônicas expressivas é possível elaborar mapas com uma qualidade aceitável utilizando-se técnicas de geoprocessamento, por exemplo, uma reclassificação dos intervalos altimétricos obtidos com um Modelo Digital de Elevação (MDE). A 
Mapa de reconhecimento geológico da bacia do rio Uberabinha (MG): procedimento experimental utilizando coeficientes de concordância

utilização estatística do mapeamento por meio de coeficientes de concordância depende de trabalhos de campo, que é uma etapa imprescindível para o levantamento da verdade terrestre, contribuindo para o melhoramento da qualidade do mapa final.

Nesse sentido, o presente artigo buscou não somente demonstrar que é possível elaborar um mapa de reconhecimento geológico com boa qualidade por intermédio desse procedimento experimental utilizando-se os coeficientes de concordância total, Kappa e Tau. Como a geologia da região está praticamente toda mapeada pela CODEMIG, foi possível ainda comparar com o resultado apresentado para a bacia do rio Uberabinha com a utilização dos arquivos vetoriais. Evidenciou-se que os dois mapas que subsidiaram o mapa final apresentaram diferenças em relação à verdade terrestre, embora tenham sido considerados de boa qualidade. Ressalta-se que a principal discrepância ocorreu em relação à área ocupada pela cobertura detrítico-laterítica, que em campo foi observada que se encontra muito dispersa, sobretudo nas porções com baixa declividade.

Em relação às demais unidades geológicas, o Grupo Araxá praticamente não sofreu alteração, sendo sua distribuição espacial nos dois mapas considerada correta. Embora os pontos de observação da Formação Serra Geral tenham abrangido essa unidade nos dois mapas, foi necessário adequar a delimitação baseado em informações diretas e indiretas analisadas em campo. Já as modificações na abrangência da Formação Marília ocorreram basicamente pela ocupação da cobertura detrítico-laterítica.

O mapa final de reconhecimento geológico da bacia do rio Uberabinha foi, dessa forma, baseado nas informações dos mapas anteriores confirmados em campo (verdade terrestre). Assim sendo, a partir dos resultados apresentados, considera-se que o mapa final de reconhecimento geológico da bacia do rio Uberabinha apresentou uma excelente qualidade e que os procedimentos podem ser aplicados em outras bacias hidrográficas situadas em contextos geotectônicos semelhantes.

\section{AGRADECIMENTOS}

O primeiro autor agradece à Coordenação de Aperfeiçoamento de Pessoal de Nível Superior (CAPES) pela concessão da bolsa de doutorado.

\section{REFERÊNCIAS}

ALVES, M. P. Petrologia e diagênese do membro Ponta Alta, Formação Marília, Cretáceo da Bacia do Paraná, na região do Triângulo Mineiro. Dissertação de Mestrado, Universidade Federal de Ouro Preto, 1995, $102 \mathrm{p}$.

BARBOSA, O.; BRAUN, O. P. C.; DYER, R. C.; CUNHA, C. A. B. R. Geologia da região do Triângulo Mineiro. Rio de Janeiro. DNPM/DFPM, 1970, 140 p.

BARCELOS, J. H. Reconstrução paleogeográfica da sedimentação do Grupo Bauru baseada na sua redefinição estratigráfica parcial em território paulista e no estudo preliminar fora do estado de São Paulo. Tese (Livre Docência), Instituto de Geociências e Ciências Exatas, Universidade Estadual Paulista, 1984, 190 p.

BATEZELLI, A. Análise da sedimentação cretácea no Triângulo Mineiro e sua correlação com áreas adjacentes. Tese de Doutorado, Programa de Pós-Graduação em Geociências Área de Concentração em Geologia Regional. UNESP - Universidade Estadual Paulista, Rio Claro, 2003, 183 p.

CODEMIG - COMPANHIA DE DESENVOLVIMENTO ECONÔMICO DE MINAS GERAIS. Programa Mapeamento Geológico do Estado de Minas Gerais. Projeto Triângulo Mineiro, 2017. Disponível em: <http://www.portalgeologia.com.br/index.php/mapa/> acesso em $14 \mathrm{de}$ março de 2018.

DARDENNE, M. A. The Brasilia fold belt. In: CORDANI, U. G.; MILANI, E. J.; THOMAZ FILHO, D.; CAMPOS, D. A. (eds.), Tectonic evolution of South America, 2000, p. 231-263. 
FELTRAN FILHO, A. A estruturação das paisagens nas chapadas do oeste mineiro. Tese (Doutorado em Geografia) - Departamento de Geografia da Faculdade de Filosofia, Letras e Ciências Humanas, Universidade de São Paulo, São Paulo, 1997, 252 p.

IBGE - INSTITUTO BRASILEIRO DE GEOGRAFIA E ESTATÍSTICA. Censo demográfico 2010. Disponível em: <https://cidades.ibge.gov.br/brasil/mg/uberlandia/panorama> acesso em 12 de março de 2018.

LISLE, R. J.; BRABHAM, P.; BARNES, J. Mapeamento geológico básico: guia geológico de campo. Tradução: Karina Sirtori, Théo Amon, Rualdo Menegat. Revisão técnica: Rualdo Menegat. $5^{\text {a }}$ ed. Porto Alegre: Bookman, 2014.

MILANI, J. M.; MELO, J. H. G. de; SOUZA, P. A. de; FERNANDES, L. A.; FRANÇA, A. B. Bacia do Paraná. B. Geoci, Petrobrás, Rio de Janeiro, v. 15, n. 2, 2007, p. 265-287.

NISHIYAMA, L. Geologia do município de Uberlândia e áreas adjacentes. Revista Sociedade e Natureza. Uberlândia: IG/UFU, v. 1, n. 1, 1989, p. 9-16.

PELLÉ, J. M. RGB Color Code according to the Commission for the Geological Map of the World (CGMW). $\quad$ France, 2012.2 Disponível em: <https://engineering.purdue.edu/Stratigraphy/charts/RGB.pdf> acesso em 12 de março de 2018.

ROSA, R. Introdução ao sensoriamento remoto. 6a ed. Uberlândia: EDUFU, 2007. https://doi.org/10.14393/EDUFU-85-7078-124-6

ROSA, R. M. Unidades de paisagem e zoneamento: subsídios para o planejamento ambiental na bacia do rio Uberabinha-MG. Dissertação (Mestrado), Universidade Federal de Uberlândia, Programa de Pós-Graduação em Geografia, 2017, 118 p.

USGS - UNITED STATES GEOLOGICAL SURVEY. Shuttle Radar Topography Mission 1 Arc-Second Global. Courtesy of the U.S. Geological Survey. Disponível em: <https://lta.cr.usgs.gov/SRTM1Arc> acesso em 18 de outubro de 2018.

Recebido em: 07/06/2018

Aceito para publicação em: 12/02/2019 